\title{
Active portfolios: diversification across trading strategies
}

\author{
C. Murray \\ Goldman Sachs and Co., New York, USA
}

\begin{abstract}
Several characteristics of a firm and its past return have been shown to be useful in predicting future returns, leading to long-short trading strategies with positive expected return using no invested capital. I develop the idea of active portfolios, which treat these long-short strategies as investable assets. I show that, since the returns from these long-short strategies are largely uncorrelated, active portfolios which make simultaneous bets on several long-short strategies have Sharpe ratios several times that of the market and extremely attractive return characteristics. I argue that this is because the diversification achievable in active portfolios exceeds that attainable through traditional sources of diversification.
\end{abstract}

Keywords: long-short trading strategies, value, momentum, diversification.

\section{Introduction}

Researchers have found a large number of long-short trading strategies that earn significant return with no invested capital. These strategies can be roughly categorized as momentum $[5,11]$, value $[3,8,9,12]$, firm size $[6,8]$ and reversal on a long $[2,7]$ and short $[10,13]$ time scale. These strategies sort stocks by one of the above criteria every month, then go long a portfolio of stocks that strongly exhibit that criteria and short a portfolio that weakly exhibit it. The return is the spread between the two portfolios. Different studies have used different samples, methodologies, and time periods to find different return spreads from these trading strategies, but a large amount of research supports the view that the above strategies have positive expected return.

I look at the performance of "active" portfolios, which treat long-short trading strategies as investable assets and which follow several strategies at once. They are "active" because the trading strategies turn over some of their capital every 
month, even if the portfolio doesn't adjust how much capital is allocated to each strategy. Just as holding many uncorrelated assets in a traditional portfolio can reduce the portfolio's variance, an active portfolio will benefit by following multiple trading strategies if their returns are uncorrelated. If all the trading strategies earn a return via exposure to one or two common underlying factors (such as a market factor or firm distress factor), then the diversification achievable in an active portfolio will not be significant. However, if the returns to the strategies are not driven by common factor exposures, an active portfolio may achieve a higher risk-adjusted return than any single strategy.

This paper's goal is to see how trading strategies interact in an active portfolio. While research like Asness [4] looks forming a trading strategy by jointly conditioning on two different variables, this paper looks at how trading strategies interact in portfolios. I find that, due to their low correlations, extremely high Sharpe ratios are achievable with active portfolios, and active portfolios don't have any alternative risk characteristics that would justify their high return.

\section{Data and methodology}

The data for zero-cost trading strategies are monthly returns from January 1956 through December 2005. All data are taken from Professor Kenneth French's Data Library, which has monthly returns for decile portfolios sorted on various criteria. I use monthly return series for equal-weight decile portfolios sorted on firm size, book-to-market, past return over the last 12 months, excluding last month (PAST(12,2)), and past return over the last 60 months, excluding the most recent year (PAST $(60,13))$. From this I create five zero-cost trading strategy return series that will be the components of active portfolios. MKT is the return of the CRSP value-weighted market portfolio minus the one month treasury rate.

HML is the return of a strategy that goes long the highest decile book-tomarket portfolio and short the lowest decile book-to-market portfolio. SMB is the return achieved going long the smallest market capitalization decile and short the largest market capitalization decile. MOM is long the decile with the highest $\operatorname{PAST}(12,2)$ and short the decile with the lowest PAST $(12,2)$.

REV is long the decile with the lowest value of PAST $(60,13)$ and short the decile highest value. A one-month reversal strategy, which was by far the most profitable, was ruled out due to high turnover. Results including this strategy are available from the author upon request.

\subsection{Trading strategies}

Summary statistics for the five trading strategies are shown in Table 1. Note that all the returns shown are zero-cost returns: they are return spreads from a long minus a short position (or in the case of the market, the return of the market minus the T-bill rate). An investor following these strategies would also earn a cash return, which isn't included. The long-short trading strategies have monthly volatilities generally of the same magnitude of the long-short market return, but 
the trading strategies tend to have higher returns and Sharpe ratios. More importantly, Table 1 shows that the return series from the trading strategies are largely uncorrelated, with an average correlation of 0.00 to two significant digits. This is what will offer the great diversification benefits in an active portfolio.

Table 1: $\quad$ Trading strategies return properties.

\begin{tabular}{lccccc}
\hline & MKT & SMB & HML & MOM & REV \\
\hline Monthly Mean Excess Return & $0.50 \%$ & $0.56 \%$ & $1.10 \%$ & $1.22 \%$ & $1.01 \%$ \\
Geometric Mean Excess Return & $0.40 \%$ & $0.44 \%$ & $1.02 \%$ & $1.03 \%$ & $0.90 \%$ \\
Monthly Volatility & $4.33 \%$ & $5.09 \%$ & $4.11 \%$ & $5.75 \%$ & $4.08 \%$ \\
Sharpe Ratio & 0.33 & 0.30 & 0.91 & 0.66 & 0.81 \\
Adjusted Sharpe Ratio & 0.31 & 0.26 & 0.81 & 0.72 & 0.71 \\
\hline & & & & & \\
\hline Correlations & MKT & SMB & HML & MOM & REV \\
\hline MKT & 1.00 & 0.05 & -0.41 & -0.09 & -0.09 \\
SMB & & 1.00 & 0.18 & -0.41 & 0.68 \\
HML & & & 1.00 & -0.04 & 0.50 \\
MOM & & & & 1.00 & -0.36 \\
REV & & & &
\end{tabular}

Table 2 looks at higher order risk characteristics of the trading strategies (again based on monthly returns). This indicates that mean-variance analysis may understate the trading strategy risk relative to the market because of the trading strategies higher kurtosis, indicating a larger probability of extreme movements, and higher autocorrelation, which leads to higher annual variance than we'd expect by naively annualizing monthly variance.

Table 2: $\quad$ Higher-order risk.

\begin{tabular}{|l|c|c|c|c|c|}
\hline & MKT & SMB & HML & MOM & REV \\
\hline Skewnes s & -0.50 & 0.99 & 0.26 & -2.79 & 2.14 \\
\hline Kurtosis & 4.94 & 6.33 & 6.21 & 27.49 & 15.32 \\
\hline ACF $(1)$ & 0.07 & 0.16 & 0.12 & -0.10 & 0.14 \\
\hline$\%$ negative & $41 \%$ & $50 \%$ & $38 \%$ & $32 \%$ & $44 \%$ \\
\hline
\end{tabular}

Autocorrelation is especially high for the SMB and HML strategies. It's well known that value strategies can have long periods of low returns [3], and the returns to the SMB strategy have been lower in the later part of the sample period than in the earlier part, leading to autocorrelation. The SMB strategies mean return declined from $0.84 \%$ per month in the first half of the sample to $0.28 \%$ in the second half. The adjusted Sharpe ratio calculated in Table 1 recalculates the annualized variance to take account of this return continuation by modeling returns as an auto-regressive model. The trading strategies' adjusted Sharpe ratios are slightly lower than their raw Sharpe ratios, but still generally higher than that of the market. Individually, the four active trading strategies (HML,SMB,MOM, and REV) seem to perform better than the market, but combining trading strategies can provide even better returns. 


\section{Active portfolios}

To see how trading strategies interact, I construct four kinds of active portfolios, each of which invests some of its capital in all of the trading strategies. An equal-weight active portfolio invests an equal amount in all trading strategies and rebalances annually. At the end of every year the magnitude of the bet on each strategy is adjusted so they are all equal again. A leveraged active portfolio is the same as the equal-weight active portfolio, but it uses leverage so that the monthly volatility of the active portfolio is the same as the average monthly volatility of the individual strategies ( $4.67 \%$ per month). The intuition is that an investor willing to engage in long-short strategies is willing to accept tradingstrategy levels of volatility, so this portfolio delivers as much return as it can for that level of volatility, while maintaining equal bets in all the strategies.

An annually-rebalanced mean-variance optimized active portfolio uses foreknowledge of the trading strategies' variance-covariance structure and returns to select portfolio weights to maximize the Sharpe ratio. The annuallyrebalanced optimized minimum-variance active portfolio similarly minimizes the variance.

The two optimized portfolios are simply for demonstration: an investor without foreknowledge of the strategies' future return and covariance structure could not have constructed these portfolios, and any investor who does have such foreknowledge needn't read journals to be successful!

Table 3: Active portfolio properties.

\begin{tabular}{|l|c|c|c|c|}
\hline Portfolio & $\begin{array}{c}\text { Equal } \\
\text { Weight }\end{array}$ & $\begin{array}{c}\text { Equal } \\
\text { Weight } \\
\text { Levered }\end{array}$ & Optimized & Min. Var. \\
\hline Leverage & 1 & 2.005 & 1 & 1 \\
\hline Monthly Mean Excess Return & $0.91 \%$ & $1.88 \%$ & $0.95 \%$ & $0.87 \%$ \\
\hline Geometric Mean Excess Return & $0.88 \%$ & $1.77 \%$ & $0.93 \%$ & $0.85 \%$ \\
\hline Monthly Volatility & $2.21 \%$ & $4.67 \%$ & $2.04 \%$ & $1.93 \%$ \\
\hline Volatility Reduction & $53 \%$ & $0 \%$ & $56 \%$ & $59 \%$ \\
\hline Annualized Sharpe Ratio: & 1.45 & 1.45 & 1.66 & 1.60 \\
\hline Adjusted Sharpe Ratio & 1.24 & 1.26 & 1.57 & 1.43 \\
\hline Higher order moments and time series properties of active portfolios & \\
\hline Skewness & 0.69 & 0.37 & -0.81 & -0.53 \\
\hline Kurtosis & 7.98 & 8.01 & 13.22 & 9.36 \\
\hline ACF(1) & 0.17 & 0.15 & 0.06 & 0.12 \\
\hline
\end{tabular}

The return properties of these active portfolios are shown in Table 3. The non-leveraged portfolios all have similar returns of just less than $1 \%$ per month, but the diversification in active portfolios drives the volatility below half the average volatility of the individual trading strategies. This reduction in volatility gives the active portfolios their extremely high Sharpe ratios. Optimization isn't required, since even the equal-weight active portfolio has superb performance, with a Sharpe ratio (1.45) and adjusted Sharpe ratio (1.24) roughly four times that of the market. The leveraged portfolio has returns of nearly $2 \%$ per month with market-like levels of volatility. Since all returns shown are zero-cost 
returns, the active portfolios short some subset of stocks, use the proceeds of the short sale to buy a long position, and then deposit the original capital in an interest-bearing account (some of which will be put up as margin). All returns shown ignore transaction and margin costs (which would reduce reported returns) but also ignore the cash return from the interest bearing account.

\section{Measures of diversification}

The high Sharpe ratios reported in the previous section come almost entirely from the fact that huge volatility reduction is achievable by investing in several trading strategies at once. Spreading an investment across just five trading strategies resulted in volatility $53 \%$ below that of the average trading strategy and $49 \%$ below the market's volatility. Since international diversification is often held up as an example of how spreading an investment in different places can benefit investors, I compare the volatility reduction in active portfolios to that in portfolios of MSCI developed country and regional indexes. All country and regional index returns are gross US dollar returns minus the US risk-free rate. Table 4 shows the basic properties of the regional index returns, the correlation across regional indexes, and each index's correlation with the MSCI world index.

Table 4: $\quad$ Regional index excess return properties: 1970-2005.

\begin{tabular}{|l|c|c|c|c|}
\hline Returns & & & & \\
\hline Monthly Mean Excess Return & Nordic & Europe & N. America & Pacific \\
\hline Geometric Mean Excess Return & $0.82 \%$ & $0.56 \%$ & $0.50 \%$ & $0.58 \%$ \\
\hline Monthly Volatility & $0.65 \%$ & $0.44 \%$ & $0.40 \%$ & $0.40 \%$ \\
\hline Sharpe Ratio & $5.86 \%$ & $4.83 \%$ & $4.39 \%$ & $6.01 \%$ \\
\hline ACF $(1)$ & 0.40 & 0.32 & 0.32 & 0.24 \\
\hline & 0.07 & 0.04 & 0.02 & 0.12 \\
\hline Correlations & & & & \\
\hline & & & & \\
\hline Nordic & Nordic & Europe & N. America & Pacific \\
\hline Europe & 1.00 & 0.73 & 0.57 & 0.47 \\
\hline N. America & & 1.00 & 0.64 & 0.55 \\
\hline Pacific & & & 1.00 & 0.39 \\
\hline World Index Correlation & 0.70 & 0.83 & 0.87 & 0.73 \\
\hline
\end{tabular}

Comparing Table 1 with Table 4, it's clear that the regional indices' individual return properties aren't that different from the trading strategy returns: the regional indexes have only slightly lower mean returns than the trading strategies with similar levels of volatility. However, the regional returns are far more correlated than the trading strategy returns, and all are tremendously correlated with the world index. The regional indexes have an average correlation of $55 \%$ with each other and almost $80 \%$ with the MSCI world index. Table 5 shows that the huge reduction in volatility reaped by building active portfolios of trading strategies doesn't occur when building portfolios of regional indexes. The equal-weight regional index portfolio only achieves a volatility 
reduction of $19 \%$ (versus the average regional index volatility), and even the optimized portfolios don't achieve a substantial increase in return or decrease in variance versus the individual regional indexes themselves. Because of this, the portfolios of regional strategies don't achieve substantially higher Sharpe ratios than the individual regional indexes, and the benefits of diversification are limited.

Table 5: $\quad$ Regional index portfolio properties: 1970-2005.

\begin{tabular}{|c|c|c|c|c|}
\hline Portfolio & $\begin{array}{l}\text { Equal } \\
\text { Weight }\end{array}$ & $\begin{array}{l}\text { Equal } \\
\text { Weight } \\
\text { Levered } \\
\end{array}$ & Optimized & Min. Var. \\
\hline Leverage & 1.00 & 1.23 & 1.00 & 1.00 \\
\hline Monthly Mean Excess Return & $0.63 \%$ & $0.77 \%$ & $0.69 \%$ & $0.53 \%$ \\
\hline Geometric Mean Excess Return & $0.53 \%$ & $0.63 \%$ & $0.59 \%$ & $0.45 \%$ \\
\hline Monthly Volatility & $4.29 \%$ & $5.27 \%$ & $4.58 \%$ & $4.02 \%$ \\
\hline Volatility Reduction & $19 \%$ & $0 \%$ & $13 \%$ & $24 \%$ \\
\hline Annualized Sharpe Ratio & 0.44 & 0.43 & 0.46 & 0.40 \\
\hline $\mathrm{ACF}(1)$ & 0.11 & 0.11 & 0.10 & 0.09 \\
\hline
\end{tabular}

Table 6: Country index portfolio properties: 1970-2005.

\begin{tabular}{|l|c|c|c|c|}
\hline & $\begin{array}{l}\text { Equal } \\
\text { Weight } \\
\text { Weight }\end{array}$ & $\begin{array}{l}\text { Levered } \\
\text { Portfolio }\end{array}$ & Optimized & Min. Var. \\
\hline Leverage & 1.00 & 1.48 & 1.00 & 1.00 \\
\hline Monthly Mean Excess Return & $0.73 \%$ & $1.11 \%$ & $0.99 \%$ & $0.55 \%$ \\
\hline Geometric Mean Excess Return & $0.63 \%$ & $0.88 \%$ & $0.86 \%$ & $0.48 \%$ \\
\hline Monthly Volatility & $4.49 \%$ & $6.62 \%$ & $5.13 \%$ & $3.81 \%$ \\
\hline Volatility Reduction & $32 \%$ & $0 \%$ & $23 \%$ & $42 \%$ \\
\hline Annualized Sharpe Ratio & 0.50 & 0.48 & 0.61 & 0.45 \\
\hline ACF(1) & 0.10 & 0.11 & 0.06 & 0.08 \\
\hline Adjusted Sharpe Ratio & 0.46 & 0.44 & 0.58 & 0.42 \\
\hline
\end{tabular}

Table 6 looks at portfolios constructed from MSCI country indexes for 14 developed countries. The country indexes are for Japan, Singapore, the USA, Australia, the U.K., Honk Kong, Switzerland, Germany, Canada, Norway, Denmark, Belgium, Sweden, and Spain. The average monthly excess return among the 14 countries over the sample period was $0.71 \%$ per year, with average monthly volatility of $6.62 \%$ and an average annualized Sharpe ratio of 0.265 . Table 6 shows returns to portfolios of country indexes. Diversifying across all 14 countries in an equal-weight portfolio gives a slightly higher Sharpe ratio (0.5) than diversifying across regional indexes, but not by much. The volatility reduction is only $32 \%$ across countries (versus the average country's volatility of $6.62 \%$ per month), while an active portfolio with just 5 trading strategies reduces the volatility by $53 \%$ (versus the average trading strategy volatility of $4.67 \%$ ). The optimized country portfolio is a little better but still can't match the volatility reduction of the equal-weight active portfolio. The levels of diversification achieved in active portfolios simply cannot be matched with traditional diversification. 


\section{Robustness checks}

Figure 1 examines the consistency of active portfolio returns over five-year subperiods between 1956 and 2005. The line shows the capital market line, using the market's average excess return and volatility over the entire period. The circles and X's are the returns and volatilities achieved by the equal weight unleveraged active portfolio over each sub-period. Sub-periods in the beginning of the sample are marked with circles while later ones are marked with X's. Figure 1 makes it clear that equal-weight active portfolios strongly dominate the return-variance outcomes achievable in the market, and these results haven't been decreasing.

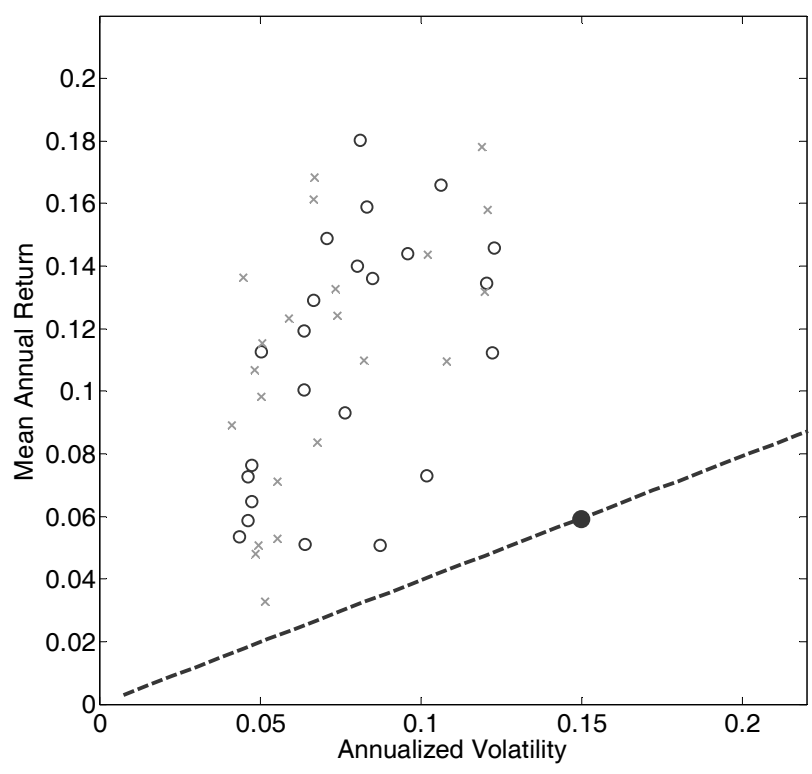

Figure 1: Mean annual excess return of the equal-weight active portfolio over every 5-year sub-period from 1956 to 2005.

\section{Conclusion}

I showed that diversification, one of the most basic tenants of investing, is extremely effective for non-traditional sources of return. Active portfolios which combine multiple long-short trading strategies achieve significant variance reduction, much more so than portfolios which spread an equity investment across countries or regions. This reduction in variance leads to extremely high Sharpe ratios for active portfolios.

I'd like to thank Kenneth French and MSCI for the use of data and Geoff Gordon and John O'Brien for helpful comments. 


\section{References}

[1] Arshanapalli, Coggin, and Doukas. Multifactor Asset Pricing Analysis of International Value Investment Strategies. Journal of Portfolio Management 24, pp. 10-23,1998.

[2] Asness, C. Variables that Explain Stock Returns. PhD Thesis, University of Chicago, 1994.

[3] Asness, C, Friedman, J., Krail, R. and Liew J. Style Timing: Value vs Growth. Journal of Portfolio Management, 26. pp 50-60, 2000.

[4] Asness, C. The Interaction of Value and Momentum Strategies. Financial Analysts Journal. pp. 29-36 1997.

[5] Asness, C., Liew, J, and Stevens, R. Parallels between the cross-sectional predictability of stock and country returns. Journal of Portfolio Management 23 pp. 79-87, 1997.

[6] Banz, R. The Relationship between return and the market value of common stocks Journal of Financial Economics, 6 pp. 103-126, 1981.

[7] De Bondt, W. and Thaler, R. Does the Stock Market Overreact? The Journal of Finance, 40 pp.793-805, 1985.

[8] Fama, E. and French, K. The Cross-Section of Expected Stock Returns. The Journal of Finance, 47 pp. 427-465, 1992.

[9] Fama, E. and French, K. Multifactor Explanations of Asset Pricing Anomalies. The Journal of Finance, $\mathbf{5 1}$ pp. 55-84, 1996.

[10] Jegadeesh, N. Evidence of predictable behavior of security returns. The Journal of Finance $\mathbf{4 5}$ pp. 881-898, 1990.

[11] Jegadeesh, N. and Titman, S. Returns to Buying Winners and Selling Losers: Implications for Stock market Efficiency. Journal of Finance, 48, pp. 65-91, 1993

[12] Lakonishok, J., Shleifer, A., and Vishny, R. Contrarian Investment, extrapolation, and Risk. The Journal of Finance 49, pp. 1541-1578, 1994.

[13] Lehmann, B. Fads, Martingales, and Market Efficiency. Quarterly Journal of Economics 105 pp.1-28, 1990. 